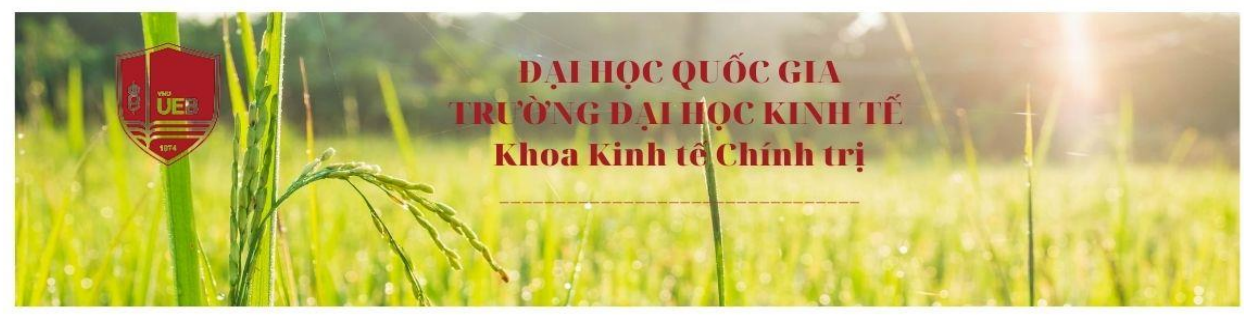

\title{
TIỂU LUẬN
}

\section{MÔN PHƯƠNG PHÁP NGHIÊN CÚU KINH TẾ}

\section{NGHIÊN CƯU VẤN ĐỀ BẢO HỘ NHÃN HIÊU GẠO VIẸTT NAM XUẤT KHẨU TẠI HOA KỲ, CÁl NHİN TỮ GAO ST25}

Giảng viên hướng dẫn: PGS.TS. LÊ ĐİNH HẢl

Nhóm thực hiện:

\section{Leonard}

1.Đỗ Thùy Trang (20051180)

2.Trần Thị Thanh Thủy (20051171)

3.Đỗ Phương Anh (20050976)

4.Ngô Thị Ngọc Bích (20051002)

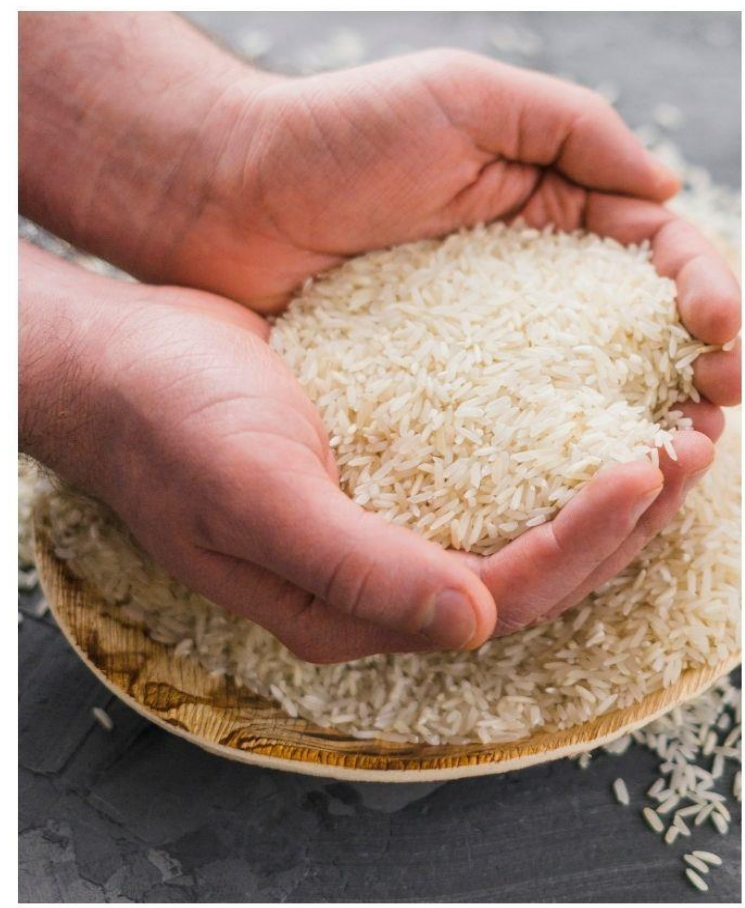




\section{LỜI CAM ĐOAN}

Chúng tôi xin cam đoan đề tài nghiên cứu: "Nghiên cứu vấn đề bảo hộ nhãn hiệu gạo Việt Nam xuất khẩu tại Hoa Kỳ, cái nhìn tù̀ Gạo ST25" của nhóm là trung thực và chưa công bố dưới bất kỳ hình thức nào trước đây. Những kết quả, số liệu phục vụ cho việc

phân tích, nhận xét, đánh giá được nhóm thu thập từ các nguồn khác nhau có ghi rõ nguồn gốc. Nhóm xin chịu hoàn toàn trách nhiệm, kỷ luật của bộ môn và nhà trường đề ra nếu như có vấn đề xảy ra.

Sinh viên 


\section{LÒ̀I CẢM ON}

Lời đầu tiên, nhóm xin chân thành cảm ơn Ban giám hiệu trường Đại học Kinh tế ĐHQGHN đã cho chúng em học tập, tiếp cận với bộ môn Phương pháp nghiên cứu kinh tế.

Nhóm xin gửi lời cảm ơn chân thành nhất đến PGS.TS.Lê Đình Hải đã nhiệt tình giúp đỡ, góp ý, chia sẻ và hướng dẫn nhóm hoàn thiện đề tài này.

Do chưa có nhiều kinh nghiệm làm đề tài cũng như những hạn chế về kiến thức, bài báo cáo chắc chắn sẽ không tránh khỏi những thiếu sót. Rất mong nhận được lời nhận xét, ý kiến đóng góp, phê bình từ phía Thầy để bài báo cáo được hoàn thiện hơn.

Lời cuối cùng, nhóm xin kính chúc thầy nhiều sức khỏe, thành công và hạnh phúc.

Hà Nội, năm 2021

Sinh viên 


\section{MỤC LỤC}

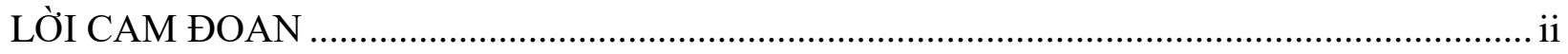

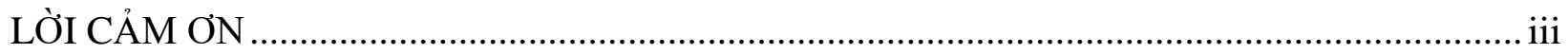

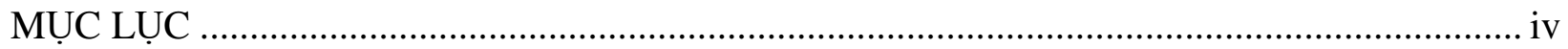

DANH MỤC CÁC TƯ VIÊT TĂT ......................................................................................... vii

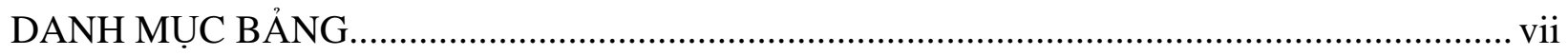

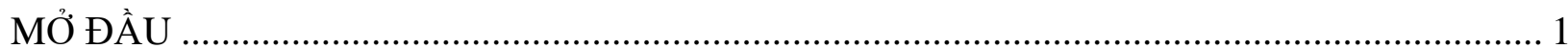

1. Tính cấp thiết của đề tài ……………………………………………………………..... 1

2. Mục tiêu và đối tượng nghiên cứu .................................................................................... 2

3. Phạm vi nghiên cứu ............................................................................................... 2

4. Câu hỏi nghiên cứu ................................................................................................ 3

5. Phương pháp nghiên cứu ............................................................................................. 3

6. Đóng góp mới của đề tài ............................................................................................... 4

7. Bố cục báo cáo nghiên cứu ………………………………………………………..... 4

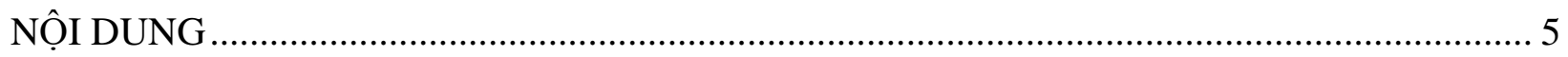

CHƯƠNG 1: TỔNG QUAN NGHIÊN CÚU ........................................................................... 5

1.1. Tổng quan tài liệu nghiên cứu trên thế giới................................................................. 5

1.2. Tổng quan tài liệu nghiên cứu ở Việt Nam .................................................................. 6

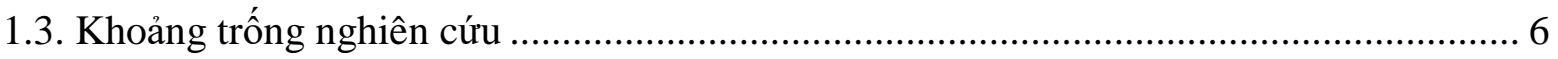

CHƯƠNG 2: CƠ SỞ LÝ LUẬN THỰC TIẼ̃N VỀ VÂN ĐỀ BẢO HỘ THƯƠNG HIỆU GẠO

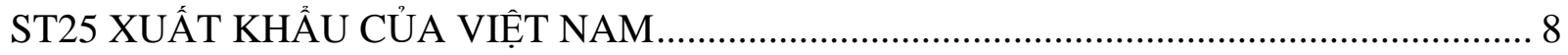

2.1. Tổng quan nhãn hiệu .................................................................................................... 8

2.1.1. Khái niệm nhãn hiệu, bảo hộ nhãn hiệu..................................................................... 8

2.1.2. Vai trò của Bảo hộ nhãn hiệu................................................................................. 8

2.1.3 Thách thức của bảo hộ nhãn hiệu cho sản phẩm xuất khẩu....................................... 10

CHƯONG 3: THỰC TRẠNG VẤN ĐÊ BẢO VỆ THƯƠNG HIỆU GẠO ST25 XUÂT

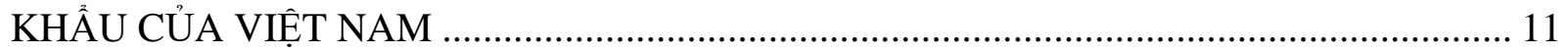

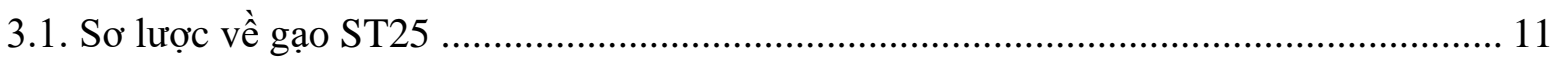

3.1.1 Nguồn gốc của giống gạo ST25 ……………………....................................... 11

3.1.2. Thực trạng sản xuất gạo ST25 trong nước và xuất khẩu sang Hoa Kỳ .................... 11 
3.1.3. Cơ hội cho xuất khẩu gạo ST25 ……………………………………………….... 12

3.1.4. Thách thức cho xuất khẩu gạo ST25 .................................................................. 13

3.1.4.1. Thách thức đối với việc đảm bảo chất lượng gạo ST25 ..................................... 13

3.1.4.2. Thách thức trong bối cảnh đại dịch Covid-19................................................ 13

3.1.4.3. Thách thức từ các thị trường gạo lớn trên thế giới........................................... 14

3.1.4.4. Thách thức trong việc bảo hộ nhãn hiệu gạo ST25 …………………………..... 14

3.2. Thực trạng vấn đề nhãn hiệu có chứa thành phần "ST25" bị đăng ký tại Hoa Kỳ......... 15

3.2.1. Thực trạng nhãn hiệu có chứa thành phần "ST25" bị đăng ký tại Hoa Kỳ ............. 15

3.2.2. Những thiếu sót trong vấn đề gạo ST25 bị đăng ký thương hiệu tại Hoa Kỳ.......... 15

3.2.2.1. Từ phía kỹ sư nghiên cứu của giống gạo và doanh nghiệp ................................ 15

3.2.2.2. Từ phía các nhà chức trách Việt Nam............................................................. 16

\section{CHƯƠNG 4: ĐỀ XUÂT GIẢI PHÁP BẢO HỘ NHÃN HIỆU GẠO VIỆT NAM XUẤT}

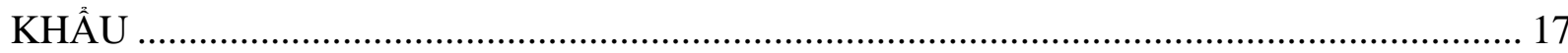

4.1. Đề xuất giải pháp đối với doanh nghiệp ..................................................................... 17

4.1.1. Xây dựng và đăng ký nhãn hiệu mang đặc trưng dễ nhận biết................................. 17

4.1.2. Chủ động tìm hiểu vấn đề bảo hộ nhãn hiệu và đăng ký bảo hộ nhãn hiệu tại thị

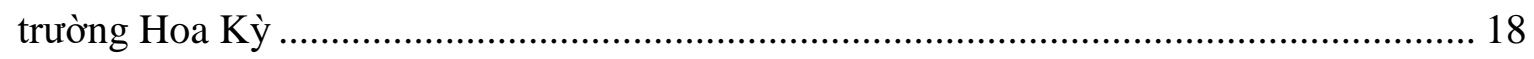

4.2. Đề xuất chính sách đối với Nhà nước.......................................................................... 19

4.2.1. Đẩy nhanh tiến độ xây dựng thương hiệu quốc gia "Gạo Việt Nam" xuất khẩu và giao nhãn hiệu chứng nhận Gạo VN/ VN Rice................................................................ 19

4.2.2. Xây dựng chính sách hỗ trợ đăng ký bảo hộ nhãn hiệu cho thương hiệu gạo Việt Nam xuất khẩu tại Hoa Kỳ..................................................................................... 20

4.2.2.1. Hỗ trợ về chuyên môn và nhận thức ………………………………………..... 20

4.2.2.2. Hỗ trợ về nguồn nhân lực................................................................................ 21

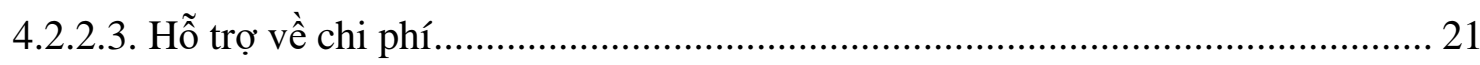

4.2.3. Tăng cường liên kết 4 nhà trong việc phát triển, định hướng và bảo hộ nhãn hiệu

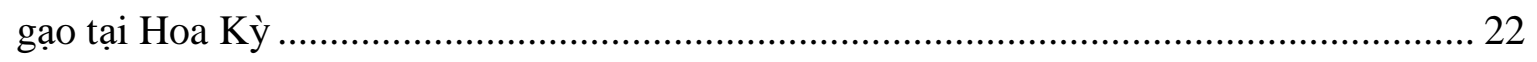

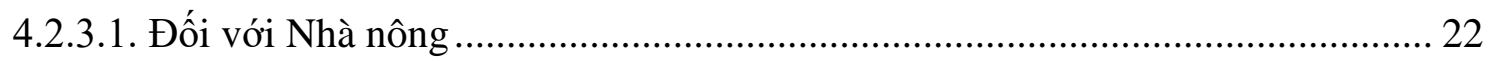

4.2.3.2. Đối với Nhà khoa học ................................................................................... 22

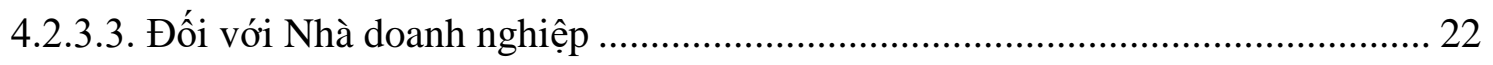

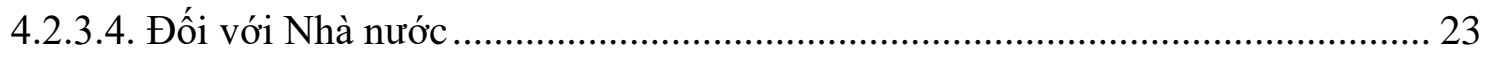

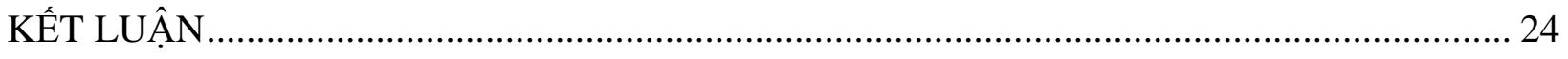


TÀI LIỆU THAM KHẢO 


\section{DANH MỤC CÁC TỬ VIẾT TÁT}

\begin{tabular}{|l|l|}
\hline DN & Doanh nghiệp \\
\hline SHTT & Sở hữu trí tuệ \\
\hline USPTO & United States Patent and Trademark Office \\
\hline VN & Việt Nam \\
\hline
\end{tabular}

\section{DANH MỤC BẢNG}

Hình 3.1. Sản lượng xuất khẩu gạo ST25 theo quý 9 tháng đầu năm 2021 


\section{MỞ ĐÀ̀U}

\section{Tính cấp thiết của đề tài}

Trong xu thế hội nhập với nền kinh tế quốc tế, Việt Nam đang ngày càng chú trọng trong việc phát triển các ngành kinh tế mũi nhọn trong đó có nông nghiệp. Với lợi thế là một đất nước độc canh cây lúa, lúa gạo vẫn là loại cây trồng chủ yếu của ngành nông nghiệp Việt Nam và có đóng góp rất lớn vào kim ngạch xuất khẩu nông sản ( khoảng 3,07 tỷ USD trong năm 2020, theo Bộ Nông nghiệp và Phát triển Nông thôn). Tuy nhiên, bên cạnh sự phát triển ngày càng mạnh mẽ của gạo Việt Nam, những rào cản đã và đang xuất hiện, điển hình là vấn đề nhãn hiệu cho từng loại gạo xuất khẩu đang phải đối mặt với vấn đề. Điều đó đặt ra vấn đề cho không chỉ các doanh nghiệp hoạt động trong lĩnh vực xuất khẩu gạo mà còn về phía Nhà nước mau chóng tìm ra điểm bất cập và giải quyết vấn đề này.

Gạo ST25 là loại gạo thơm Sóc Trăng, kết quả 20 năm ròng rã nghiên cứu của kỹ sư Hồ Quang Cua và được công nhận là loại gạo ngon nhất thế giới. Giống gạo này đã được xếp vào hàng những loại gạo "thượng hạng” trên thế giới sau khi xuất sắc đạt danh hiệu "Gạo ngon nhất thế giới năm 2019” và giải Nhì tại cuộc thi "Gạo ngon nhất thế giới 2020" tại Mỹ. Nói riêng về mặt giá trị, loại gạo này đã thực sự trở thành niềm tự hào cho ngành nông nghiệp Việt Nam và hứa hẹn sẽ đem lại nguồn lợi nhuận khổng lồ khi chính thức được bày bán trên thị trường nước ngoài. Tuy nhiên, sau khi ông Vũ Bá Phú- Cục trưởng Cục xúc tiến thương mại (Bộ Công thương), thông tin gạo ST25 bị 5 doanh nghiệp Mỹ. Từ đó chúng ta thấy rằng, vấn đề bảo hộ nhãn hiệu gạo đang là một vấn đề quan trọng. Trước vấn đề cấp thiết này, chính doanh nghiệp cũng như người nghiên cứu ra giống gạo này cùng với Nhà nước phải có những giải pháp tối ưu nhất nhằm giải quyết vấn đề đó.

Vì những lý do nêu trên, đề tài : "Nghiên cứu vấn đề bảo hộ nhãn hiệu gạo Việt Nam xuất khẩu tại Hoa Kỳ, cái nhìn tù̀ Gạo ST25" được nghiên cứu với mục đích đưa ra những nhìn nhận cụ thể về vấn đề bảo hộ nhãn hiệu gạo có chứa thành phần ST25 xuất khẩu, từ đó đề ra một số giải pháp khắc phục vấn đề và đẩy mạnh phát triển đăng ký bảo hộ sở hữu trí tuệ cho nhãn hiệu gạo xuất khẩu. 


\section{Mục tiêu và đối tượng nghiên cứu}

\subsection{Mục tiêu nghiên cứu}

\subsubsection{Mục tiêu tổng quát}

Trên cơ sở các lý thuyết về vấn đề bảo vệ nhãn hiệu, thông qua việc nghiên cứu thực trạng vấn đề bảo hộ nhãn hiệu gạo có chứa thành phần ST25 xuất khẩu của Việt Nam, xác định được những khó khăn, hạn chế trong vấn đề bảo hộ nhãn hiệu. Từ đó đề xuất một số giải pháp nhằm bảo hộ nhãn hiệu gạo xuất khẩu của Việt Nam sang các thị trường quốc tế trong thời gian tới.

\subsubsection{Mục tiêu cụ thể}

- Hệ thống hóa và làm rõ các khái niệm về nhãn hiệu, bảo hộ nhãn hiệu và kinh nghiệp bảo hộ nhãn hiệu của các quốc gia.

- Nghiên cứu thực trạng bảo hộ nhãn hiệu đối với mặt hàng gạo VN xuất khẩu tại Hoa Kỳ.

- Phân tích cụ thể thực trạng bảo hộ nhãn hiệu gạo có chứa thành phần ST25 xuất khẩu.

- Đánh giá và đề xuất các giải pháp nhằm bảo hộ nhãn hiệu gạo xuất khẩu của Việt Nam sang các thị trường quốc tế trong thời gian tới.

\section{2. Đối tuộng nghiên cúu}

Vấn đề bảo hộ nhãn hiệu gạo xuất khẩu của Việt Nam tại Hoa Kỳ.

\section{Phạm vi nghiên cứu}

\subsection{Phạm vi về nội dung}

Trong nghiên cứu vấn đề bảo hộ nhãn hiệu gạo việt nam xuất khẩu, bài nghiên cứu sẽ tiến hành nghiên cứu các khái niệm nhãn hiệu, bảo hộ nhãn hiệu, vấn đề tồn tại của nhãn hiệu gạo (gạo việt nam xuất khẩu sang thị trường Hoa Kỳ). Nghiên cứu thực trạng nhãn hiệu gạo bị đăng ký nhãn hiệu có chứa thành phần ST25, từ đó phân tích những yếu tố liên 
quan đến vấn đề bảo hộ nhãn hiệu. Từ nghiên cứu thực trạng trên sẽ trở thành tiền đề cho việc đề xuất những giải pháp và chính sách kịp thời cho vấn đề này.

\subsection{Phạm vi về không gian}

Nhãn hiệu gạo Việt Nam xuất khẩu tại Hoa Kỳ

\subsection{Phạm vi về thời gian}

Nghiên cứu tình hình xuất khẩu gạo ST25 trong năm 2020 và 3 quý đầu năm 2021

\section{Câu hỏi nghiên cứu}

Để nghiên cứu đề tài này, nhóm sẽ tiến hành nghiên cứu và trả lời các câu hỏi sau:

- Nhãn hiệu và bảo hộ nhãn hiệu là gì? Vai trò của bảo hộ nhãn hiệu là gì? Kinh nghiệm về bảo hộ nhãn hiệu của các quốc gia?

- Thưc trạng các nhãn hiệu gạo bảo hộ nhãn hiệu tại Hoa Kỳ nhu thế nào?

- Thực trạng cu thể về vấn đề bảo vệ nhãn hiệu có chứa thành phần gạo ST25 như thế nào?

- Giải pháp cần có để giải quyết vấn đề bảo hộ nhãn hiệu cho thuoong hiệu gạo xuất khẩu là gì?

\section{Phương pháp nghiên cứu}

Đề tài sử dụng phối hợp các phương pháp nghiên cứu sau:

- Phuơng pháp thu thập tài liệu: Bài nghiên cứu sử dụng phương pháp thu thập dữ liệu thứ cấp từ nhiều nguồn thông tin khác nhau như: ITC, Tổng cục Thống kê, World Bank, các tạp chí kinh tế, luận án, luận văn,... trong nước và nước ngoài.

- Phuoong pháp xử lý thông tin: thông tin được sử dụng trực tiếp và tổng hợp bằng nhiều công cụ: bảng biểu, sơ đồ, đồ thị, ... để đánh giá quy mô, bản chất và xu hướng thay đổi của đối tượng nghiên cứu theo thời gian và không gian. 


\section{6. Đóng góp mới của đề tài}

Dựa trên tổng quan nghiên cứu trong và ngoài nước, đóng góp mới của đề tài gồm có:

- Phân tích thực trạng thực tế từ cái nhìn gạo ST25: Vấn đề bảo hộ nhãn hiệu có chứa thành phần ST25 tại Hoa Kỳ.

- Từ thực trạng đó đề xuất những giải pháp, kiến nghị phù hợp nhằm giải quyết vấn đề bảo hộ nhãn hiệu cho doanh nghiệp và nhãn hiệu gạo xuất khẩu nói chung.

\section{Bố cục báo cáo nghiên cứu}

Chương 1: Tổng quan nghiên cứu

Chương 2: Cơ sở lý luận và thực tiễn về vấn đề bảo hộ thương hiệu gạo ST25 xuất khẩu của Việt Nam

Chương 3: Thực trạng vấn đề bảo hộ thương hiệu gạo ST25 xuất khẩu của Việt Nam

Chương 4: Đề xuất giải pháp tháo gỡ rào cản thương hiệu cho giống gạo ST25 


\section{NỘI DUNG}

\section{CHƯƠNG 1: TỔNG QUAN NGHIÊN CÚU}

\subsection{Tổng quan tài liệu nghiên cứu trên thế giới}

Trên thế giới đã có các công trình, các báo cáo nghiên cứu về vấn đề bảo hộ thương hiệu gạo. Một số công trình điển hình như:

Theo Kranti Mulik và John M. Crespi (2010): Các hình thức bảo hộ quyền sở hữu trí tuệ khác nhau như nhãn hiệu, chỉ dẫn địa lý và bằng sáng chế đã có từ lâu. Nhưng không giống như các nước công nghiệp phát triển có lịch sử bảo hộ tài sản trí tuệ lâu đời của mình, việc bảo hộ pháp lý tài sản trí tuệ vẫn còn tương đối mới đối với các nước đang phát triển. Ở các thị trường đang phát triển hiện đang chú trọng nhiều đến việc giảm thuế quan và hạn ngạch mà tương đối ít chú ý đến việc tăng cường hệ thống quyền sở hữu trí tuệ (Geographical Indications and The Trade Related Intellectual Property Rights Agreement (TRIPS): A Case Study of Basmati Rice Exports)

Theo Panpilas Kuldilok (2018), các nhà phát triển nhãn hiệu rõ ràng nhấn mạnh nhiều hơn vào các thành phần cụ thể hơn là các thành phần trừu tượng gây ra sự thiếu nhận dạng nhãn hiệu trong việc phát triển các yếu tố không ổn định của thương hiệu. Về truyền thông thương hiệu, hầu hết các nhà phát triển thương hiệu gạo Thái Lan không có kế hoạch từng bước truyền thông thương hiệu của mình, đây là một điểm yếu đáng kể cần cải thiện. Bài nghiên cứu cũng đã đưa ra một số giải pháp cho các nhà phát triển thương hiệu để cải thiện tình hình truyền thông của thương hiệu gạo. (The development of prototype brading for sustainable rice from small-scaled farming in Thailand)

Theo Emodi và Peter Nwachukwu (2019), hình ảnh nhãn hiệu, tên nhãn hiệu, định hướng nhãn hiệu và lòng trung thành nhãn hiệu có ảnh hưởng đáng kể đến sự bảo trợ của người tiêu dùng đối với gạo chế biến tại chỗ ở Đông Nam Nigeria. Dựa trên những phát hiện, nghiên cứu kết luận rằng chiến lược xây dựng thương hiệu có ảnh hưởng đáng kể đến sự bảo trợ của người tiêu dùng đối với gạo chế biến tại chỗ ở Đông Nam Nigeria. Nghiên cứu khuyến nghị rằng các nhà sản xuất nông sản nên bao bì và xây dựng thương hiệu vì nó 
sẽ cải thiện hiệu suất tiếp thị của họ (Effect Of Branding On Consumer Patronage Of Locally Processed Rice In South East Nigeria).

\subsection{Tổng quan tài liệu nghiên cứu ở Việt Nam}

Theo TS. Bùi Văn Quang (2016), qua việc phân tích xây dựng các thương hiệu gạo, phân tích về sản xuất, xuất khẩu và xây dựng thương hiệu gạo Việt trong những năm gần đây, tác giả đã chỉ ra nguyên nhân và đề ra các phương án để xây dựng thương hiệu gạo Việt Nam trong tương lai. Nghiên cứu kết luận rằng xây dựng thương hiệu gạo Việt Nam có một vai trò quan trọng trong việc tăng giá trị của sản phẩm, dễ dàng xâm nhập các thị trường, nâng cao khả năng cạnh tranh, kích thích sản xuất và cải thiện phát triển kinh tế xã hội (Thực trạng và giải pháp xây dụng thưong hiệu gạo Việt Nam)

Theo MSC, Nguyễn Thị Phan Thu (2021), nhờ kiểm soát được hợp lý đại dịch Covid-19, Việt Nam đã có cơ hội để phát triển thương hiệu gạo Việt. Tuy nhiên, việc tập trung chủ yếu vào số lượng thay vì tập trung vào chất lượng gạo đã khiến gạo Việt đang dần đánh mất những thị trường lớn và tiềm năng như các nước ở Châu Âu, Châu Mỹ vào tay các đối thủ như Thái Lan, Trung Quốc hay Ấn Độ. Những loại gạo như ST25, ST24, Hạt Ngọc Trời cũng chưa được xây dựng thương hiệu một cách hiệu quả do chính sách gạo của Chính phủ không nhất quán, doanh nghiệp thiếu quan tâm và liên kết lỏng lẻo (Giải pháp xây dụng thương hiệu gạo Việt Nam)

\subsection{Khoảng trống nghiên cứu}

Dựa trên tổng quan nghiên cứu tài liệu trong và ngoài nước, có thể thấy rằng vấn đề bảo hộ nhãn hiệu là một trong những vấn đề đón nhận được rất nhiều sự quan tâm hiện nay. Việc chú trọng xây dựng nhãn hiệu, phát triển nhãn hiệu và cơ chế bảo hộ nhãn hiệu hợp lý sẽ là một bệ phóng giúp cho hàng hóa thích nghi với thị trường tốt hơn, độ nhận diện cao hơn và tiếp cận gần hơn với người tiêu dùng.

Tổng quan trong nước cho thấy việc phát triển xây dựng thương hiệu gạo Việt Nam cũng đã và đang được cân nhắc dựa trên tình hình phát triển kinh tế hiện tại của nước ta. 
Tuy nhiên, vấn đề bảo hộ nhãn hiệu chưa nhận được nhiều sự nghiên cứu với từng đối tượng cụ thể tại Việt Nam đặc biệt là trường hợp từ gạo ST25. Cụ thể hóa vấn đề chính là việc nhãn hiệu có chứa thành phần ST25 bị tự ý đăng ký tại thị trường Hoa Kỳ. Việc nghiên cứu về vấn đề này sẽ cho ta thấy khoảng trống trong cơ chế bảo hộ nhãn hiệu cho hàng hóa xuất khẩu tại Việt Nam, sự thờ ơ và chủ quan đến từ phía doanh nghiệp và sự thiếu kiểm soát đến từ phía giới chức trách Việt Nam. Đó là những lý do để chúng ta cần cấp thiết đi tiến hành nghiên cứu vấn đề này. 


\section{CHƯƠNG 2: CƠ SỞ LÝ LUẬN THỰC TIỄN VỀ VẤN ĐỀ BẢO Hộ THƯƠNG HIỆU GẠO ST25 XUẤT KHẨU CỦA VIỆT NAM}

\subsection{Tổng quan nhãn hiệu}

\subsubsection{Khái niệm nhãn hiệu, bảo hộ nhãn hiệu}

\subsubsection{Khái niệm nhãn hiệu}

Nhãn hiệu (trademark) theo định nghĩa của Tổ chức sở hữu trí tuệ thế giới (WIPO): nhãn hiệu là "các dấu hiệu dùng để phân biệt hàng hoá, dịch vụ cùng loại hoặc tương tự của các cơ sở sản xuất, kinh doanh khác nhau”. Các dấu hiệu được sử dụng như một nhãn hiệu là một dấu hiệu có thể nhìn thấy, có thể dưới dạng chữ cái, từ ngữ, hình vẽ, hình ảnh, bao gồm các dạng ba chiều hoặc kết hợp các yếu tố trên và được biểu thị bằng một hoặc nhiều màu.

\subsubsection{Khái niệm bảo hộ nhãn hiệu}

Bảo hộ nhãn hiệu đề cập đến việc bảo vệ quyền sở hữu trí tuệ để bảo vệ nhãn hiệu khỏi bị làm giả và vi phạm. Chủ sở hữu nhãn hiệu có thể nộp đơn để đăng ký bảo hộ nhãn hiệu. Điều quan trọng cần lưu ý là quyền sở hữu trí tuệ là quyền có tính lãnh thổ, nghĩa là chúng chỉ được bảo hộ trong lãnh thổ của một quốc gia hoặc trong một khu vực mà chúng được đăng ký và bảo hộ. Do đó, một công ty đã nộp đơn đăng ký bảo hộ nhãn hiệu tại thị trường nội địa của mình sẽ không được sự bảo hộ ở thị trường xuất khẩu, trừ khi các quyền đó đã được đăng ký và được cấp bởi cơ quan sở hữu trí tuệ quốc gia (hoặc khu vực) của thị trường xuất khẩu có liên quan.

\subsubsection{Vai trò của Bảo hộ nhãn hiệu}

Trong nền kinh tế thị trường ngày nay, nhãn hiệu có vai trò rất lớn đối với sự phát triển của doanh nghiệp. Tuy nhiên, một thực trạng khá phổ biến hiện nay là các hình thức xâm phạm nhãn hiệu như sao chép, làm nhái, lấy nhãn hiệu gần giống hoặc gợi liên tưởng đang là vấn đề được các doanh nghiệp và xã hội quan tâm. Vì vậy, việc bảo hộ nhãn hiệu là rất quan trọng, thể hiện ở những điểm sau: 
Thứ nhất, góp phần nâng cao giá trị sản phẩm và giá trị của doanh nghiệp. Nhãn hiệu hàng hóa tạo ra giá trị cho sản phẩm, khách hàng sẽ rất sẵn lòng trả giá cao hơn để được sử dụng sản phẩm/dịch vụ mang thương hiệu mà họ yêu thích. Đồng thời, họ cũng sẵn sàng sử dụng sản phẩm/dịch vụ đó thường xuyên hơn, vì vậy, giá trị mang lại cho doanh nghiệp sẽ cao hơn. Chính vì thế, việc đăng ký độc quyền nhãn hiệu là việc làm nhằm tạo ra sự khác biệt giữa sản phẩm, dịch vụ của mình với những sản phẩm, dịch vụ cùng loại khác và đây cũng chính là một trong những phương pháp nâng cao giá trị sản phẩm và giá trị của doanh nghiệp.

Thứ hai, bảo vệ quyền lọi chính đáng cho người tiêu dùng. Người tiêu dùng là một chủ thể quan trọng và không thể thiếu hiện nay để tạo nên một thị trường đa dạng và sôi động. Trong cuộc sống công việc bận rộn hàng ngày, và với vô số sản phẩm và dịch vụ luôn đáp ứng nhu cầu của mọi khách hàng thì dường như việc dành thời gian để lựa chọn những sản phẩm yêu thích và cần thiết là không thể. Việc mua nhầm sẽ xảy ra thường xuyên hơn và có thể dẫn đến những hậu quả khó lường. Chính vì vậy, việc bảo hộ nhãn hiệu là công cụ hữu hiệu nhất để bảo vệ người tiêu dùng lúc này.

Thứ ba, bảo hộ thưong hiệu là bảo hộ lọi ích quốc gia. Vì nhãn hiệu chỉ có tính chất lãnh thổ nên nhãn hiệu đã được bảo hộ toàn bộ tại Việt Nam sẽ không được bảo hộ ở các quốc gia khác trừ khi nhãn hiệu đó được đăng ký tại quốc gia đó. Trên thực tế, những năm gần đây, nhiều doanh nghiệp Việt Nam đã thành công trong việc tạo ra những sản phẩm có mẫu mã đẹp, chất lượng tốt, từ đó tạo được uy tín trong lòng người tiêu dùng. Tuy nhiên, các doanh nghiệp Việt Nam khi đưa sản phẩm ra thị trường nước ngoài một phần vì thiếu hiểu biết, một vài phần chậm trễ đã tạo điều kiện cho các doanh nghiệp nước ngoài có thể chiếm đoạt được nhãn hiệu của mình bằng cách đăng ký bảo hộ nhãn hiệu trên thị trường xuất khẩu. Kết quả là chúng ta mất đi thị trường tiềm năng ở nước ngoài. Đây là một tổn thất lớn đối với nền kinh tế Việt Nam khi GNI phần lớn là đóng góp doanh thu của thị trường xuất khẩu. 


\subsubsection{Thách thức của bảo hộ nhãn hiệu cho sản phẩm xuất khẩu}

Trong hội thảo trực tuyến do Cục Sở hữu trí tuệ tổ chức, PGS.TS. Nguyễn Quốc Thịnh, Đại học Thương mại đã chỉ ra ba rào cản khiến các DN Việt Nam vẫn chần chừ chưa muốn đăng ký nhãn hiệu ở nước ngoài. Thứ nhất là do nhận thức của các chủ $\mathrm{DN}$, nhiều chủ DN xem DN của mình nhỏ, bán sản phẩm ra nước ngoài thông qua một nhà nhập khẩu thì trách nhiệm ở nước ngoài là của nhà nhập khẩu, ít quan tâm đến trách nhiệm và việc bảo vệ lợi ích của chính mình.

Trở ngại thứ hai là thủ tục ở các thị trường khác nhau cũng rất khác nhau. Khi các DN gặp phải rào cản về luật pháp và ngôn ngữ, họ trở nên chán nản. Cuối cùng là chi phí đăng ký tại một số thị trường cũng là gánh nặng cho các $\mathrm{DN}$. 


\section{CHƯƠNG 3: THỰC TRẠNG VẤN ĐỀ BẢO VỆ THƯƠNG HIỆU GẠO ST25 XUẤT KHẨU CỦA VIẸTT NAM}

\subsection{So lược về gạo $\mathrm{ST25}$}

\subsubsection{Nguồn gốc của giống gạo ST25}

ST25 là giống lúa do kỹ sư Hồ Quang Cua nghiên cứu và phát triển từ giống lúa thơm đặc sản của tỉnh Sóc Trăng.

Gạo ST25 là loại gạo hạt dài, trắng trong, không bạc bụng, khi nấu cơm dẻo thơm, có vị ngọt tự nhiên, khi để nguội cơm vẫn ngon và mềm. Gạo ST25 có hàm lượng đạm cao thích hợp với nhiều đối tượng khách hàng. Bên cạnh đó, ST25 được trồng theo phương pháp hữu cơ, không sử dụng phân bón, thuốc trừ sâu, thuốc diệt cỏ, hoặc thuốc trừ sâu hay bất kỳ loại thuốc bảo vệ thực vật nào.

Chất lượng gạo ST25 đã được quốc tế công nhận khi được vinh danh là Gạo ngon nhất thế giới năm 2019 trong Cuộc thi Gạo ngon nhất thế giới (World’s Best Rice do The Rice Trader) thuộc Hội nghị Thương mại Gạo Thế giới lần thứ 11 được tổ chức tại Philippines và giải nhì cuộc thi "Gạo ngon nhất thế giới 2020” tại Hoa Kỳ.

\subsubsection{Thục trạng sản xuất gạo ST25 trong nước và xuất khẩu sang Hoa Kỳ}

Mặc dù được vinh danh là gạo ngon nhất thế giới từ năm 2019 nhưng sản lượng gạo ST25 xuất khẩu ra nước ngoài trong cả năm 2020 chỉ đạt hơn 1200 tấn. Tính đến đầu năm 2021, gạo ST25 mới được xuất khẩu mạnh đi các quốc gia trên thế giới, và phần lớn là được nhập khẩu bởi thị trường Hoa Kỳ

- Trong quý I/2021, tổng khối lượng xuất khẩu đạt gần 1900 tấn. Trong đó thị trường Hoa Kỳ chiếm tỷ trọng $98 \%$

- Trong 6 tháng đầu năm xuất khẩu 2,7 nghìn tấn gạo ST25. Trong đó thị trường Hoa Kỳ chiếm tỷ trọng $95 \%$

- Trong 9 tháng đầu năm 2021, tổng khối lượng ST25 xuất khẩu sang Hoa Kỳ khoảng 2.800 tấn, chiếm đến $91 \%$ tổng khối lượng xuất khẩu gạo của nước ta, tăng $843 \%$ so với cùng kỳ 


\section{Biểu đồ 1. Sản lượng xuất khẩu gạo ST25 theo quý 9 tháng đầu năm 2021}

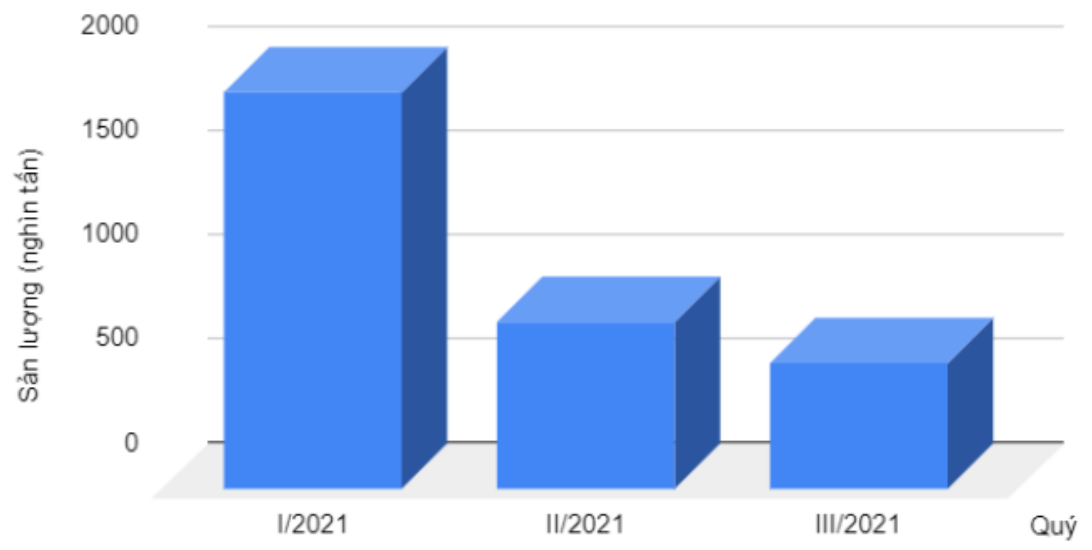

Nguồn: Theo Tổng cục Hải quan

Hình 3.1. Sản lương xuất khẩu gạo ST25 theo quý 9 tháng đầu năm 2021

\subsubsection{Co hội cho xuất khẩu gạo ST25}

Thứ nhất, Gạo ST25 đã giành được danh hiệu gạo ngon nhất thế giới và mang đến cho Việt Nam cơ hội vàng để xây dựng nhãn hiệu cho gạo của mình. Sản phẩm này không chỉ quảng bá cho gạo Việt Nam trên thị trường quốc tế mà nó còn là động lực thúc đẩy nông dân, doanh nhân đầu tư sản xuất gạo chất lượng cao trong thời hội nhập. Đặc biệt khi nhu cầu toàn cầu ngày càng tăng đã tạo cho Việt Nam rất nhiều cơ hội lớn.

Thứ hai, giống lúa ST25 thích nghi cao với sự biến động của môi trường, có khả năng chịu mặn, chịu phèn cao hơn các giống lúa khác, có đặc tính kháng sâu bệnh tốt. Và đặc biệt, giống lúa ST25 có thời gian sinh trưởng và phát triển ngắn nên mỗi năm có thể canh tác nhiều vụ mùa, tăng sản lượng lúa mỗi năm để tiêu thụ tại thị trường trong nước và xuất khẩu ra thế giới.

Thứ $b a$, gạo ST25 đang được ngày càng nhiều quốc gia trên thế giới biết đến, mở rộng thị trường xuất khẩu sang 11 quốc gia. Đặc biệt, gạo ST25 đã đáp ứng được những tiêu chuẩn khắt khe của những thị trường khó tính như Hoa Kỳ, EU,... Đây cũng là cơ hội để chất lượng của gạo ST25 được biết đến nhiều hơn trên thế giới. Cùng với đó là việc Việt 
Nam tham gia ký kết nhiều hiệp định thương mại như EVFTA, RCEP... tạo ra nhiều cơ hội hơn cho thị trường xuất khẩu gạo.

Thư tur, quy trình sản xuất gạo sử dụng công nghệ Châu Âu tiên tiến, hiện đại, đẹp mắt, tạo ra những hạt gạo sạch, đẹp, chất lượng cao, đáp ứng được các tiêu chuẩn khắt khe của các thị trường nhập khẩu trên thế giới.

Thứ năm, tiêu dùng gạo thơm là xu hướng đang phát triển trong những năm gần đây của thế giới. Do vậy, gạo thơm ST25 - "Gạo ngon nhất thế giới” sẽ trở thành một trong những lựa chọn hàng đầu của người tiêu dùng trên thế giới.

\subsubsection{Thách thức cho xuất khẩu gạo ST25}

\subsubsection{Thách thức đối với việc đảm bảo chất lựng gạo ST25}

Gạo ST25 của Việt Nam không chỉ cần quan tâm đến sản lượng mà còn cần đặc biệt chú trọng đến chất lượng gạo để đáp ứng được các tiêu chuẩn khắt khe của các thị trường lớn trên thế giới như: Hoa Kỳ, Hàn Quốc... Gạo ST25 cần phải đáp ứng các tiêu chí về nguồn đất, nguồn nước, về sử dụng đúng liều lượng thuốc bảo vệ thực vật và phân bón hóa học, không có dư lượng thuốc bảo vệ thực vật, hóa chất độc hại gây ảnh hưởng đến sức khỏe của người tiêu dùng, đảm bảo vệ sinh an toàn thực phẩm. Hiện nay, gạo ST25 xuất khẩu chưa hoàn toàn được yêu cầu về chất lượng (quá mức dư lượng tối đa thuốc bảo vệ thực vật, không đảm bảo yêu cầu về vệ sinh an toàn thực phẩm). Đây không phải là vấn đề mới trong thị trường xuất khẩu gạo của Việt $\mathrm{Nam}$, do vậy việc kiểm soát và đảm bảo chất lượng gạo ST25 xuất khẩu cũng là một thách thức không nhỏ.

\subsubsection{Thách thức trong bối cảnh đại dịch Covid-19}

Trong tình hình đại dịch Covid-19 bùng phát phức tạp, việc xuất khẩu gạo ST25 sang các thị trường nước ngoài chịu ảnh hưởng nghiêm trọng: khối lượng xuất khẩu giảm mạnh (quý 3/2021, chỉ đạt 395 tấn), chi phí vận chuyển tăng cao (có thời điểm giá thuê container sang Hoa Kỳ lên đến 22.000 USD), các chuyến hàng nhiều lúc bị trễ (thậm chí còn bị hoãn)... Đồng thời, diễn biến phức tạp của dịch Covid-19 đã gây trở ngại cho việc 
thu hoạch và sản xuất lúa ở các tỉnh phía Nam. Điều này cũng được coi là một thách thức lớn đối với thị trường xuất khẩu gạo của Việt Nam tại thời điểm hiện nay.

\subsubsection{Thách thức tù̀ các thị truờng gạo lớn trên thế giới}

Ngành gạo Việt Nam đang phải đối mặt với sự cạnh tranh rất gay gắt trên thị trường xuất khẩu gạo, khi mà các nước đối thủ như Thái Lan và Ấn Độ liên tục điều chỉnh giá gạo xuất khẩu. Theo Hiệp hội Lương thực Việt Nam, tính đến phiên giao dịch ngày 3/5/2021, giá gạo xuất khẩu của Việt Nam đã sụt giảm mạnh so với ngày 26/3/2021. Cụ thể, gạo 5\% tấm có giá 483-487 USD/tấn (giảm 35 USD/tấn); gạo 25\% tấm giá 458-462 USD/tấn (giảm 30 USD/tấn); gạo 100\% tấm 423-427 USD/tấn (15 USD/tấn). Hiện nay, gạo ở các nước Thái Lan, Ấn Độ đã điều chỉnh giá gạo xuất khẩu xuống mức thấp, điều này đã giúp họ chiếm ưu thế lớn trên các thị trường. Do vậy, các $\mathrm{DN}$ xuất khẩu gạo của Việt Nam cũng phải liên tục điều chỉnh mức giá gạo để cạnh tranh.

\subsubsection{Thách thức trong việc bảo hộ nhãn hiệu gạo ST25}

Về mặt nhãn hiệu, các loại “gạo ngon nhất thế giới” là ST25 của Việt Nam thời gian gần đây liên tục bị các DN nước ngoài rập rình bảo hộ thương hiệu. Sau vụ 5 DN Mỹ gửi hồ sơ đăng ký bảo hộ thương hiệu loại gạo này, điều này không khỏi dấy lên lo ngại các nhãn hiệu gạo Việt đứng trước nguy cơ bị rơi vào tay $\mathrm{DN}$ nước ngoài.

Bên cạnh thị trường tiêu thụ gạo ST25 là Mỹ, theo đại diện Thương vụ Việt Nam tại nước Anh cho hay "Chương trình nhãn hiệu quốc gia cần lựa chọn một số chủng loại gạo chất lượng cao có sản lượng lớn để đặt tên theo hướng đơn giản, dễ nhớ, dễ phát âm và gắn với địa danh nơi trồng lúa, ví dụ như gạo Sóc Trăng Việt Nam hay tên người tạo ra giống lúa như: Gạo Ông Cua để có thể đăng ký bảo hộ thuận lợi tại nước ngoài. Đáng tiếc, gạo ST25 tuy đã được giải thưởng là gạo ngon nhất thế giới năm 2019 nhưng rất ít người dân Anh biết đến và không có nhiều hiệu quả marketing trên thị trường Anh". Để có thể tạo ra đột phá thị trường cũng như là nâng cao vị thế cho hạt gạo Việt Nam, đây cũng là một thách thức đòi hỏi ngành lúa gạo Việt Nam phải nhanh chóng triển khai một chiến lược thương hiệu phù hợp với từng thị trường. 


\subsection{Thực trạng vấn đề nhãn hiệu có chứa thành phần "ST25" bị đăng ký tại Hoa Kỳ}

\subsubsection{Thục trạng nhãn hiệu có chứa thành phần "ST25" bị đăng ký tại Hoa Kỳ}

USPTO đã nhận được các đơn sau cho các sản phẩm gạo (Nhóm 29):

+ Đơn số 90270383 “The World's Best Rice Gao Thom ST25 Dac san Soc Trang”, ngày nộp 22/10/2020; người nộp đơn: Ngon Fish Sauce, Inc. CORPORATION CALIFORNIA

+ Đơn số 90151727 “"Vietnam's ST25 Rice, Dac San Soc Trang”, Foods, Inc. CORPORATION CALIFORNIA

+ Đơn số 90085988 “No.1 Vietnam's ST25 Rice The World's Best Rice”, ngày nộp 31/07/2020; người nộp đơn: Transworld Foods, Inc. CORPORATION CALIFORNIA

+ Đơn số 90009521 “ST25”, ngày nộp 18/06/2020, người nộp đơn: I\&T ENTERPRISE, INC. CORPORATION CALIFORNIA

+ Đơn số 90103840, “ST25”, ngày nộp 10/08/2020, người nộp đơn: TTM International Inc CORPORATION CALIFORNIA

Tuy nhiên, các đơn đăng ký trên đều không thành công. Nguyên nhân là trong đơn đăng ký có sử dụng tên "ST25", mà "ST25 chỉ là tên gọi của một giống lúa, là tên chung, mô tả thực vật hoặc hạt giống, nên theo quy định không được bảo hộ nhãn hiệu". Những sự kiện này cũng được xem là bài học đối với các doanh nghiệp xuất khẩu gạo của Việt Nam trong việc đăng ký bảo hộ nhãn hiệu gạo có chứa dấu hiệu "ST25".

\subsubsection{Những thiếu sót trong vấn đề gạo ST25 bị đăng ký thưong hiệu tại Hoa Kỳ}

\subsubsection{Tù̀ phía kỹ sur nghiên cứu của giống gạo và doanh nghiệp}

Theo Luật Sở hữu trí tuệ, "ST25" là tên giống lúa, khi chủ sở hữu văn bằng bảo hộ hoặc bất kỳ người nào đưa sản phẩm lúa giống đó ra thị trường thì đều phải dùng tên ST25, kể cả sau khi hết thời gian bảo hộ thì bất kỳ ai còn sử dụng giống lúa đó cũng đều phải gọi 
là giống ST25. Do vậy, gạo ST25 được sử dụng như một tên gọi thông thường của hàng hóa. Mà một tên gọi thông thường, theo Luật Sở hữu trí tuệ thì không được bảo hộ.

Bên cạnh vấn đề tên gọi thì sự thiếu chủ động của kỹ sư nghiên cứu trong việc đăng ký bảo hộ nhãn hiệu sớm cũng là một trong những nguyên nhân khiến gạo ST25 bị doanh nghiệp hay cá nhân khác đăng ký trước. Cùng với đó, các doanh nghiệp xuất khẩu gạo ST25 đi nước ngoài cũng chưa để tâm đến việc tra cứu và đăng ký bảo hộ nhãn hiệu trước khi đưa sản phẩm ra nước ngoài.

\subsubsection{Tù̀ phía các nhà chức trách Việt Nam}

Nhà nước mới chỉ cấp bằng bảo hộ giống cây trồng tại Việt Nam cho tác giả Hồ Quang Cua, đồng tác giả Trần Tấn Phương, Nguyễn Thị Thu Hương thuộc sở hữu của Doanh nghiệp tư nhân Hồ Quang Trí mà chưa hề hề có bất kỳ bằng bảo hộ nhãn hiệu nào được cấp đối với các nhãn hiệu chứa dấu hiệu “ST25”. Đặc biệt, sau khi gạo ST25 được vinh danh là "Gạo ngon nhất thế giới” năm 2019 thì chính phủ cũng chưa có chiến lược nào rõ ràng, cụ thể để bảo hộ và quảng bá cho nhãn hiệu gạo ST25. Đây là điều mà các nhà chức trách của Việt Nam nên xem xét và sửa đổi, tránh xảy ra những trường hợp bị ăn cắp nhãn hiệu như gạo ST25. 


\section{CHƯƠNG 4: ĐỀ XUẤT GIẢI PHÁP BẢO Hộ NHÃN HIỆU GẠO VIỆT NAM XUẤT KHẨU}

Từ thực tế tại Việt Nam cho thấy, trước đây gạo Nàng thơm Chợ Đào cũng đã từng bị đăng ký trước bản quyền tại Mỹ cho đến thời điểm hiện tại là vấn đề nhãn hiệu gạo có chứa thành phần ST25 bị 5 doanh nghiệp đăng ký bản quyền tại Mỹ. Nếu chỉ nhìn sơ qua, thì nhiều người và nhiều doanh nghiệp vẫn còn bàng quan về vấn đề bảo hộ nhãn hiệu này. Tuy nhiên, đặt trong bối cảnh Việt Nam đang hướng tới nền kinh tế hội nhập toàn cầu, việc xuất khẩu là điều giúp Việt Nam khẳng định vị thế trên thị trường. Mặt hàng gạo xuất khẩu cũng được coi là một trong những mặt hàng xuất khẩu chủ lực của Việt Nam, song vấn đề bảo hộ nhãn hiệu này nếu còn tiếp diễn xảy ra thì chính là rào cản ngăn bước phát triển giao thương xuất khẩu của Việt Nam tại Hoa Kỳ. Điều này đặt ra không chỉ doanh nghiệp mà còn có phía Nhà nước nên có những quyết sách, hướng đi cụ thể nhằm "phòng bệnh hơn chữa bệnh", xây dựng một phòng tuyến kiên cố giúp mặt hàng gạo xuất khẩu không bị “ăn cắp nhãn hiệu” tại thị trường chủ lực Hoa Kỳ.

\section{1. Đề xuất giải pháp đối với doanh nghiệp}

Dựa trên thực tiễn cái nhìn từ gạo ST25, có thể thấy được rằng một trong những bất cập dẫn đến vấn đề bị đăng ký trước nhãn hiệu có chứa thành phần ST25 đến từ sự chủ quan của doanh nghiệp. Rút ra bài học từ thực tiễn đó, các doanh nghiệp hoạt động trong lĩnh vực sản xuất gạo xuất khẩu nên có những giải pháp kịp thời sau.

\subsubsection{Xây dụng và đăng ký nhãn hiệu mang đặc trung dễ nhận biết}

Từ cái nhìn gạo ST25, đặt ra cho các doanh nghiệp nên có những suy nghĩ, tư duy đúng đắn và cẩn trọng hơn trong việc xây dựng nhãn hiệu riêng cho sản phẩm của mình khi xuất khẩu sang thị trường Hoa Kỳ. Theo hướng dẫn thẩm định đơn đăng ký nhãn hiệu của USPTO Cơ quan sáng chế và nhãn hiệu Hoa Kỳ, thẩm định viên sẽ từ chối đơn đăng ký nhãn hiệu đối với tên giống cây trồng. Mặt khác, nhìn lại một số mặt hàng gạo Việt Nam xuất khẩu, tên nhãn hiệu của một số loại gạo thường xuất phát từ nơi giống lúa được trồng, hoặc được lấy ra từ tên của chính giống lúa, như ví dụ gạo thành phẩm ST25 được gọi dựa trên tên giống gạo ST25. Như vậy, doanh nghiệp cần suy xét lại trong việc xây 
dựng nhãn hiệu cụ thể cho mặt hàng gạo xuất khẩu của mình, xây dựng nhãn hiệu nổi tiếng, thay vì xây dựng nhãn hiệu chung chung từ tên giống gạo.

Việc xây dựng nhãn hiệu cốt lõi, mang đặc trưng riêng của mặt hàng sẽ giúp cho các doanh nghiệp có bước tiến mạnh mẽ hơn trong việc sở hữu nhãn hiệu đặc trưng.

\subsubsection{Chủ động tìm hiểu vấn đề bảo hộ nhãn hiệu và đăng ký bảo hộ nhãn hiệu tại}

\section{thị trường Hoa Kỳ}

Theo quy định của Luật sở hữu trí tuệ tại Việt Nam, một loại hàng hóa được đăng ký bảo hộ nhãn hiệu tại Việt Nam không đồng nghĩa với việc nó cũng được bảo hộ nhãn hiệu tại các quốc gia trên thế giới. Nói cách khác, khi doanh nghiệp xác định hướng tới xuất khẩu hàng hóa sang thị trường Hoa Kỳ, nó đồng nghĩa với việc doanh nghiệp phải tuân thủ đúng những điều lệ quốc tế và nguyên tắc để bảo hộ nhãn hiệu, hàng hóa của mình. Vấn đề này đặt ra cho doanh nghiệp trước khi xác định xuất khẩu sang thị trường Hoa Kỳ cần tìm hiểu rõ về cơ chế bảo hộ nhãn hiệu tại đây, nghiên cứu rõ ràng cụ thể các quy định về quyền bảo hộ sở hữu trí tuệ.

Thực tế cho thấy, việc bảo hộ sở hữu trí tuệ cho mặt hàng gạo xuất khẩu của nước ta tại Hoa Kỳ không nhiều, trong đó hai trường hợp điển hình nhất đều đã từng trải qua quá trình khó khăn trong việc bảo hộ lại nhãn hiệu vốn dĩ thuộc về doanh nghiệp mình. Bên cạnh đó, bảo hộ sở hữu trí tuệ cho mặt hàng gạo xuất khẩu của nước ta tăng tính cạnh tranh với gạo xuất khẩu của các nước như Ân Độ, Thái Lan.. Như vậy, điều đó hoàn toàn có thể lý giải tại sao gạo Việt Nam xuất khẩu dù chất lượng tốt, mặt hàng được ưa chuộng nhưng lại không thu về doanh thu cao, giá thành gạo thấp hơn so với các loại gạo của Ân Độ hay Thái Lan. Hơn thế nữa, khả năng cạnh tranh của gạo Việt Nam so với gạo Ấn Độ hay Thái lan sẽ thấp hơn rất nhiều, khó khăn trong việc tiếp cận và mở rộng thị trường cũng như khách hàng sẽ khó có thể nhớ đến gạo Việt Nam chính chủ. Mặt khác, ta đặt ra câu hỏi tại sao gạo Ân Độ và Thái Lan, dù chất lượng không đảm bảo 100\% ngon hơn gạo Việt Nam nhưng tính cạnh tranh và giá trên từng kg rất cao? Đơn cử ở việc các loại gạo của hai nước trên đều đã được đăng ký bảo hộ trên thị trường Mỹ, và hơn hết họ cũng đã từng trải qua sự ăn cắp bản quyền nhãn hiệu, chỉ dẫn địa lý trước đó. Họ cũng đã mất một khoảng thời gian loay hoay tìm lối đi đúng và sau cùng, họ cũng thành công trong việc bảo hộ. Sau 
những thực tế từ chính Việt Nam cũng như những lợi ích mà nó mang lại khi đăng ký bảo hộ nhãn hiệu, các doanh nghiệp Việt Nam cần chủ động trong hoàn thành đăng ký bảo hộ nhãn hiệu cho mặt hàng xuất khẩu của mình.

Bên cạnh đó, doanh nghiệp cần tìm hiểu về các quy trình đăng ký bảo hộ nhãn hiệu tại thị trường Hoa Kỳ. Trên thực tế, việc đăng ký bảo hộ nhãn hiệu tại đây là cả một quá trình dài và chi phí cao để tiến hành thủ tục, chính vì thế, doanh nghiệp nên cẩn trọng trong việc tìm kiếm nguồn lực như luật sư, văn phòng luật sư đại diện.. nhằm gửi đơn đăng ký bảo hộ nhãn hiệu lên USPTO một cách nhanh chóng và hiệu quả nhất.

\section{2. Đề xuất chính sách đối với Nhà nước}

\subsection{1. Đẩy nhanh tiến độ xây dụng thương hiệu quốc gia "Gạo Việt Nam"xuất khẩu} và giao nhãn hiệu chứng nhận Gạo VN/VN Rice

Bên cạnh đăng ký bảo hộ nhãn hiệu tại thị trường Hoa Kỳ, một trong những lý do giúp gạo Ấn Độ và Thái Lan phát triển mạnh mẽ hơn nhiều so với gạo nước ta chính là ở việc xây dựng thương hiệu quốc gia cho tất cả các loại gạo xuất khẩu. Nhìn lại nước ta, số lượng các loại gạo Việt Nam xuất khẩu rất nhiều, tuy nhiên, điều chúng ta thiếu ở đây chính là việc định hình một vị thế thương hiệu riêng nhằm nâng cao tính cạnh tranh, tính nhận diện trên thị trường gạo xuất khẩu Việt Nam.

Trong Đề án phát triển THQG gạo Việt Nam đến năm 2020 tầm nhìn 2030 được Thủ tướng Chính phủ phê duyệt năm 2015, đây được coi là bước đi mang tính bước ngoặt khi đặt ra yêu cầu cho gạo $\mathrm{VN}$ xuất khẩu học hỏi kinh nghiệm của các quốc gia khác như Thái Lan, Ân Độ. Tuy nhiên, cho đến năm 2021 hiện nay là đã 6 năm trôi qua, nhưng thực chất đề án này của Chính phủ vẫn chưa đi đến những bước hiệu quả vốn được định ra trước đó. Bằng chứng qua việc, đến ngày 19/10/2021, Bộ Nông nghiệp và Phát triển nông thôn mới có Tờ trình số 6726/TTr-BNN-CB TTNS kiến nghị Thủ tướng Chính phủ cấp nhãn hiệu chứng nhận gạo Việt Nam/ Vietnam Rice cho các đơn vị, doanh nghiệp kinh doanh, xuất khẩu gạo. Vậy câu hỏi đặt ra, cho đến thời điểm nào thì những nhãn hiệu này chính thức được "đến tay” các doanh nghiệp?

Vấn đề này không phải là vấn đề có thể sửa đổi trong ngắn hạn, tuy nhiên, dựa trên tình hình phát triển mặt hàng gạo $\mathrm{VN}$ xuất khẩu, Chính phủ nên có những bước đi chắc 
chắn và gọn lẹ hơn trong việc xây dựng phòng tuyến vững chắc, tạo vị thế cho thương hiệu gạo VN và nhãn hiệu cho từng mặt hàng gạo nói riêng.

\subsubsection{Xây dưng chính sách hỗ trọ đăng ký bảo hộ nhãn hiệu cho thương hiệu gạo} Việt Nam xuất khẩu tại Hoa Kỳ

Tại Việt Nam, phần lớn doanh nghiệp tham gia kinh doanh và sản xuất xuất khẩu gạo đều còn gặp nhiều rào cản trong việc thực hiện đăng ký bảo hộ nhãn hiệu tại thị trường Hoa Kỳ như rào cản về nhận thức, kinh phí hay năng lực chuyên môn... Điều này đặt ra cho Chính phủ nên có những quyết sách cụ thể nhằm giải quyết triệt để những vấn đề đó. Trong đó, những chính sách hỗ trợ cụ thể gồm ba hướng đề xuất như sau.

\subsubsection{Hố trọ về chuyên môn và nhận thức}

Một trong số những rào cản tiên quyết và tối quan trọng đã cản trở các DN hoạt động trong thị trường gạo xuất khẩu đăng ký bảo hộ nhãn hiệu chính là rào cản về nhận thức. Trên thực tế, hầu hết các $\mathrm{DN}$ đều không nhận thức đủ về tầm quan trọng của nhãn hiệu cũng như bảo hộ nhãn hiệu. Họ đinh ninh rằng chỉ cần đăng ký nhãn hiệu và bảo hộ nhãn hiệu tại Việt Nam thì có thể xuất khẩu đi các nước mà không lo bị ăn cắp bản quyền tên nhãn hiệu, không làm bị giả danh, giả mạo. Nhưng, bất cứ một loại hàng hóa xuất khẩu nào khi xuất khẩu mà không bảo hộ hay đăng ký nhãn hiệu tại thị trường đang hướng tới thì đều là mục tiêu của những doanh nghiệp nước ngoài. Đây chính là vấn đề xuất phát từ tâm lý, nhận thức của $\mathrm{DN}$ và chủ sở hữu $\mathrm{DN}$, quá thờ ơ trong những vấn đề mang tính sống còn của hàng hóa mình sản xuất ra.

Thứ nhất, Chính phủ nên có những chính sách cụ thể và rõ ràng trong việc tổ chức những chương trình đào tạo, huấn luyện về tầm quan trọng của nhãn hiệu và bảo hộ nhãn hiệu đến với rộng rãi các DN hoạt động kinh doanh xuất khẩu gạo.

Thư hai, Việt Nam đã tham gia vào Công ước Paris về bảo hộ sở hữu công nghiệp cho phép các $\mathrm{DN}$ được đăng ký ở hầu hết các nước trên thế giới và cũng đã là thành viên của Thỏa ước và Nghị định thư Madrid về đăng ký quốc tế nhãn hiệu. Chính vì vậy, từ thực tiễn nói trên mà Chính phủ nên có những chương trình đào tạo bài bản về chuyên môn và cách tiếp cận đến hệ thống đăng ký nhãn hiệu nói trên đến rộng khắp các doanh nghiệp hoạt động kinh doanh, sản xuất trong thị trường này. 


\subsubsection{Hỗ trọ về nguồn nhân lục}

Bên cạnh hỗ trợ về chuyên môn cho các DN thì nguồn nhân lực là nhân tố không thể thiếu trong những chính sách hỗ trợ này. Thừa nhận rằng, thủ tục và chu trình đăng ký bảo hộ nhãn hiệu tại thị trường Hoa Kỳ đòi hỏi một khoảng thời gian dài và nhiều công đoạn khác nhau. Mặt khác, các DN tại Việt Nam còn gặp quá nhiều rào cản về ngôn ngữ, chuyên môn. Như vậy, vấn đề đặt ra cho Chính phủ chính là triển khai mạnh mẽ chính sách hỗ trợ nguồn nhân lực cho các DN trong quá trình thực hiện đăng ký bảo hộ nhãn hiệu.

Thứ nhất, hỗ trợ nguồn nhân lực trong việc tư vấn, hỗ trợ quá trình đăng ký bảo hộ nhãn hiệu như sự hỗ trợ đến từ Cơ quan Nhà nước, Cục SHTT về chu trình đăng ký, mẫu đơn đăng ký cho đến khi đơn đăng ký bảo hộ nhãn hiệu được gửi lên USPTO. Thứ hai, tăng cường sự hỗ trợ đăng ký bảo hộ nhãn hiệu qua việc thành lập Cơ quan, tổ tư vấn hỗ trợ cho DN tại thị trường Hoa Kỳ thông qua Đại sứ quán Việt Nam tại Hoa Kỳ hoặc các văn phòng luật tư nhân được nhận ủy quyền bởi Nhà nước tại Hoa Kỳ. Điều này giúp các DN được làm việc trực tiếp tại Hoa Kỳ và giải quyết tất cả những tình huống khẩn cấp xảy ra một cách nhanh chóng nhất. Thứ ba, đẩy mạnh phát triển những kênh thông tin, truyền thông trực tuyến trên trang web chính thức của Cục SHTT, cụ thể về tổ tư vấn trực tuyến, những thông tin cần thiết về chu trình đăng ký bảo hộ nhãn hiệu tại Hoa Kỳ.

\subsubsection{Hỗ trọ' về chi phí}

Chi phí đăng ký bảo hộ nhãn hiệu được coi là một trong những rào cản hàng đầu đối với các $\mathrm{DN}$ hoạt động trong thị trường này. Trên thực tế, hầu hết các $\mathrm{DN}$ đều là doanh nghiệp vừa và nhỏ, song song với đó, xuất phát từ tâm lý chung mà họ không muốn đánh cược một số tiền lớn cho việc đăng ký bảo hộ nhãn hiệu trong khi họ còn chưa biết sản phẩm gạo của mình tại thị trường Mỹ có kiếm được nguồn thu ổn định hay không. Đây chính là vấn đề mà Chính phủ phải giải quyết.

Một lẽ tất yếu, không chỉ đăng ký bảo hộ nhãn hiệu tại Hoa Kỳ mà đăng ký tại bất kỳ quốc gia nào cũng như vậy, nó đều sẽ mất một khoản kinh phí lớn. Chính điều đó cũng tạo nên tâm lý e ngại cho DN. Từ điều đó, đặt ra cho Cơ quan Nhà nước và địa phương nên có những chính sách cụ thể hóa hỗ trợ về kinh phí tối ưu cho các DN có thể hoàn thành thủ tục để hoàn thiện quá trình đăng ký nói trên. 


\subsubsection{Tăng cuờng liên kết 4 nhà trong việc phát triển, định hướng và bảo hộ nhãn hiệu gạo tại Hoa Kỳ}

Liên kết 4 nhà "Nhà nông - Nhà nước - Nhà khoa học - Nhà doanh nghiệp" - mô hình này từ lâu đã được coi là xu thế phát triển tất yếu và được Việt Nam triển khai rộng rãi trong thị trường gạo nói riêng và thị trường nông sản nói chung. Đặt trong vấn đề bảo hộ nhãn hiệu, chúng tôi muốn đề xuất chính sách này nhằm hỗ trợ tối đa cho ngành gạo Việt Nam xuất khẩu cụ thể như sau.

\subsubsection{1. Đối với Nhà nông}

Đối với vai trò của Nhà nông trong việc trồng lúa chính là áp dụng công nghệ liên kết, xây dựng chuỗi giá trị liên kết mặt hàng gạo với nhau thành từng vùng chuyên canh cụ thể. Song song với đó là hạn chế sử dụng hàm lượng cao hóa chất trong phân bón nhằm tạo ra thành phẩm là hạt gạo đạt chuẩn chất lượng cao, không chứa những hóa chất quá biên độ cho phép. Điều này sẽ giúp cho hạt gạo Việt Nam nắm trọn được thị trường khó tính như Hoa Kỳ. Bên cạnh đó, áp dụng mô hình thâm canh, tăng vụ, cơ giới hóa các quy trình trồng lúa nhằm tối thiểu hóa sức người và tối đa hóa sản lượng lúa thu hoạch. Điều này giúp cho nguồn cung lúa của nước ta luôn được đảm bảo và được xuất đi hàng ngày.

\subsubsection{2. Đối với Nhà khoa học}

Lấy ví dụ từ ông Hồ Quang Cua- một người đã dành ra hơn 10 năm cuộc đời mình, dành trọn sự tâm huyết với sự nghiệp trồng lúa nước từ ngàn đời của cha ông ta. Ông ấy đã tự nghiên cứu ra cho mình giống lúa tuyệt vời, cho ra thành phẩm gạo ST25 từ chính sự tận tâm của mình. Nhờ bước đệm này, các nhà khoa học, các kỹ sư nông nghiệp, nên chú trọng nhiều hơn trong việc tìm ra những giống lúa mới phù hợp với thị hiếu thị trường, phù hợp với thổ nhưỡng từng vùng miền tại Việt Nam. Điều đó sẽ giúp VN phát huy được lợi thế vốn có của mình về nền nông nghiệp trồng lúa.

\subsubsection{3. Đối với Nhà doanh nghiệp}

Thứ nhất. đẩy mạnh sự liên kết với người dân thành lập các Hợp tác xã chuyên môn nhằm tạo ra nguồn cung gạo lớn theo chuẩn đầu ra. 
Thư hai, đẩy mạnh công tác nghiên cứu thị trường Hoa Kỳ để hoàn thiện bệ phóng cần thiết cho quá trình đưa gạo Việt Nam sang kinh doanh tại thị trường đó. Cụ thể ở đây chính là xây dựng nhãn hiệu gạo xuất khẩu hợp lý, đảm bảo sản phẩm của mình, nhãn hiệu của mình không có bất kỳ tác động nào hoặc sai phạm nào trong các điều luật tại Việt Nam và tại Hoa Kỳ. Song song với đó, tìm hiểu cụ thể, rõ ràng về những quy định trong bảo hộ quyền SHTT, tìm hiểu về chu trình đăng ký bảo hộ nhãn hiệu tại thị trường xuất khẩu. Chủ động đăng ký bảo hộ nhãn hiệu tạo phòng tuyến mạnh mẽ nhất cho danh tiếng và chất lượng gạo Việt Nam xuất khẩu tại Hoa Kỳ.

\subsubsection{4. Đối với Nhà nước}

Thứ nhất, Nhà nước đẩy mạnh hợp tác với doanh nghiệp trong việc kiểm định chất lượng sản phẩm gạo xuất khẩu, nhằm đảm bảo chất lượng hàng hóa tốt nhất khi được xuất sang một thị trường khó tính như Hoa Kỳ.

Thư hai, trong vấn đề bảo hộ nhãn hiệu. Nhà nước hỗ trợ DN trong việc đăng ký nhãn hiệu tại chính Việt Nam cũng như hỗ trợ nguồn nhân lực, vật lực, chi phí kịp thời cho chu trình đăng ký bảo hộ nhãn hiệu tại nước ngoài. Cụ thể hóa, Nhà nước nên có những chính sách về năng lực chuyên môn cho các $\mathrm{DN}$, hỗ trợ về nguồn nhân lực đảm bảo luôn hoạt động để hỗ trợ các DN trong việc thông tin về vấn đề đăng ký bảo hộ nhãn hiệu qua sự liên kết giữa Cục Sở hữu trí tuệ- Bộ Nông nghiệp và Phát triển nông thôn- Bộ Khoa học và Công nghệ. Bên cạnh đó, đưa ra những chính sách hỗ trợ về vốn, chi phí nhằm giúp các DN giải vây trong việc tiến hành các chu trình đăng ký bảo hộ nhãn hiệu. 


\section{KẾT LUẬN}

Bảo vệ nhãn hiệu là bảo vệ thị trường kinh doanh, bảo vệ nhãn hiệu cho hàng hóa Việt Nam ở nước ngoài là mở rộng thị trường tiêu thụ hàng hóa đó ra thế giới.

\section{Bài "Nghiên cứu vấn đề bảo hộ nhãn hiệu gạo Việt Nam xuất khẩu tại Hoa Kỳ,} cái nhìn tù̀ Gạo ST25” đã chỉ ra được thực trạng nhãn hiệu bị đăng ký bởi các doanh nghiệp, cá nhân nước ngoài tại thị trường Mỹ, đồng thời cũng đề xuất một số giải pháp đối với Nhà nước, doanh nghiệp cũng như là kỹ sư nghiên cứu và người nông dân.

Hy vọng qua bài nghiên cứu, Nhà nước cùng tất cả các bên liên quan đều có thể quan tâm, chú trọng đến vấn đề bảo hộ nhãn hiệu nhiều hơn để tránh trường hợp các hàng hóa khác cũng bị đăng ký nhãn hiệu giống với trường hợp của gạo ST25. 


\section{TÀI LIỆU THAM KHẢO}

[1] Bảo hộ nhãn hiệu cho doanh nghiệp: Không chỉ dừng ở việc đăng ký, Bộ Khoa Học và Công Nghệ- Cục Sở Hữu Trí Tuệ. (2021).

https://www.ipvietnam.gov.vn/vi_VN/web/guest/tin-tuc-su-kien/-

/asset_publisher/7xsjBfqhCDAV/content/bao-ho-nhan-hieu-cho-doanh-nghiepkhong-chi-dung-o-viec-ang-ky.

[2] N.T.H. Bích, Bảo hộ nhãn hiệu nổi tiếng theo pháp luật liên minh châu âu và bài học kinh nghiệm cho vấn đề bảo hộ nhãn hiệu nổi tiếng tại Việt Nam, (2012).

[3] H. Giang, Bảo hộ nhãn hiệu ở nước ngoài: Không để doanh nghiệp chông chênh, Báo Điện Tử Chính Phủ Nước Cộng Hòa XHCN Việt Nam. (2021). https://www.google.com/url?q=http://baochinhphu.vn/Thi-truong/Bao-ho-nhanhieu-o-nuoc-ngoai-Khong-de-doanh-nghiep-chongchenh/438570.vgp\&sa=D\&source=docs\&ust=1641748816647510\&usg=AOvVaw 13snvDq6ESKb-SRE4IwM9I.

[4] Bảo hộ nhãn hiệu ở nước ngoài: Không để doanh nghiệp chông chênh, (2021). http://sokhcn.vinhphuc.gov.vn/noidung/tintuc/Lists/SoHuuChiTue/View_Detail.as px?ItemID=1698.

[5] P. Nwachukwu, Effect Of Branding On Consumer Patronage Of Locally Processed Rice In South East Nigeria, (2019). https://seahipaj.org/journals-ci/dec2019/IJBLR/full/IJBLR-D-3-2019.pdf (accessed December 8, 2021).

[6] Gạo ST25 bắt đầu khan hàng tại Mỹ, VOV.Vn. (2021). https://www.google.com/url?q=https://vov.vn/kinh-te/thi-truong/gao-st25-bat-daukhan-hang-tai-my883815.vov\&sa $=$ D\&source $=$ docs \&ust $=1641748483489793 \&$ usg $=$ AOvVaw3wgjzq VSsQTXkZqH8WoAFh.

[7] N.T. Tuyên, Gạo ST25 và câu chuyện xây dựng, bảo hộ thương hiệu, (2021). 
https://www.google.com/url?q=https://lawfirmelite.com/gao-st25-va-bao-hothuonghieu/\&sa=D\&source=docs\&ust $=1641748052567242 \& u s g=A O v V a w 2 d q F T 2 n N k$ WeK4MSv61A3Hx.

[8] T. Trang, Gạo Việt xuất khẩu sang Anh năm 2020 tăng 116\%, Báo Tin Tức- Thông Tấn Xã Việt Nam. (2021). https://baotintuc.vn/kinh-te/gao-viet-xuat-khau-sanganh-nam-2020-tang-116-20210504162254420.htm.

[9] K. Mulik, J.M. Crespi, Geographical indications and the trade related intellectual property rights agreement (TRIPS): A case study of basmati rice exports, J. Agric. Food Ind. Organ. 9 (2011). https://doi.org/10.2202/1542-0485.1336/HTML.

[10] B. Van Danh, Joining TPP and intellectual property protection: Case of Vietnam, Tap Chi Cong Thuong. (2016) 1028-1029.

[11] Khái niệm “nhãn hiệu” và “thương hiệu," VietAnLaw. (2021). https://luatvietan.vn/khai-niem-nhan-hieu-va-thuong-hieu.html.

[12] Kỷ yếu hội thảo Xây dựng và bảo vệ thương hiệu - Trường Đại học Tài chính Marketing, (2017).

[13] H. Trần, Liên kết “4 nhà” trong nông nghiệp đã thực sự hiệu quả?, Báo Người Lao Động. (2018). https://www.google.com/url?q=https://nld.com.vn/kinh-te/lien-ket4-nha-trong-nong-nghiep-da-thuc-su-hieu-qua20181109174814045.htm\&sa $=\mathrm{D} \&$ source $=$ docs \&ust $=1641748753252345 \&$ usg $=\mathrm{A}$ OvVaw1EblSS9K_SpgxMpbEwbl1E.

[14] Ecolife, Mở rộng diện tích sản xuất gạo ST25 ngon nhất thế giới, (2021). http://thienngaden.vn/am-thuc/mo-rong-dien-tich-san-xuat-gao-st25.html.

[15] Một số vấn đề liên quan đến thông tin thương hiệu gạo ST25 bị “đánh cắp" tại Hoa Kỳ, Bộ Khoa Học và Công Nghệ- Cục Sở Hữu Trí Tuệ. (2021). 
https://www.google.com/url?q=https://www.ipvietnam.gov.vn/tin-tuc-su-kien//asset_publisher/7xsjBfqhCDAV/content/mot-so-van-e-lien-quan-en-thong-tinthuong-hieu-gao-st25-bi-anh-cap-tai-hoaky\&sa=D\&source $=$ docs \&ust $=1641748890297222 \& u s g=$ AOvVaw1GPHusF1lbXx vun.

[16] J. Rice Crisis, B. Lerson Tanasugarn, L. Tanasugarn, New Challenges in IPRs Protections: Biological Diversity \& Biotechnology Jasmine Rice Crisis A Thai Perspective, Lerson.Sc.Chula.Ac.Th. (1998). http://www.lerson.sc.chula.ac.th/bc/pdf/tech_management/jasmine_rice_crisis.pdf (accessed November 13, 2021).

[17] Nhìn lại quá trình đăng ký nhãn hiệu có chứa thành phần ST25 tại Hoa Kỳ, Pham\&Associates. (2021). https://www.pham.com.vn/tin-tuc-su-kien/nhin-lai-quatrinh-dang-ky-nhan-hieu-co-chua-thanh-phan-st25-tai-hoa-ky.html.

[18] V.N. Diệp, No Title, Cafef. (2021). https://cafef.vn/nhu-cau-gao-thom-tai-my-tangmanh-co-hoi-cho-xuat-khau-gao-viet-nam-20211004094614479.chn.

[19] T. Chung, No Title, Vinanet. (2018). https://vinanet.vn/thuong-mai-cha/nam-2017xuat-khau-gao-tang-truong-vuot-muc-tieu-687341.html.

[20] No Title, Báo Điện Tử Đảng Cộng Sản Việt Nam. (2015). https://dangcongsan.vn/kinh-te/xay-dung-thuong-hieu-quoc-gia-gao-viet-nam323187.html.

[21] B. Van Quang, Situation and solution to build brand of Vietnam Rice, Vietnam Trade and Industry view, 2016.

[22] P.G.S. Jörn H. Blocka, b,*, Christian O. Fischa, Alexander Hahnc, Why do SMEs file trademarks? Insights from firms in innovative industries, (2015).

[23] Xây dựng, quản lý và phát triển chỉ dẫn địa lý, nhãn hiệu chứng nhận và nhãn hiệu 
tập thể, Bộ Khoa Học và Công Nghệ- Cục Sở Hữu Trí Tuệ. (2019).

https://www.google.com/url?q=https://ipvietnam.gov.vn/phat-trien-chi-dan-ia-ly//asset_publisher/SGA9PgvmYtWI/content/thuc-trang-trong-xay-dung-quan-ly-vaphat-trien-chi-dan-ia-ly-nhan-hieu-chung-nhan-va-nhan-hieu-tapthe?inheritRedirect\%3Dfalse\&sa=D\&sour.

[24] D. Hưng, Xuất khẩu gạo đang gặp khó, Báo Tiền Phong. (2021). https://tienphong.vn/xuat-khau-gao-dang-gap-kho-post1333914.tpo.

[25] H.Mĩ, Xuất khẩu gạo ST25 trong quý $\mathrm{I} / 2021$ tăng 375 lần, vượt con số của cả năm 2020, Vietnambiz. (2021).

https://www.google.com/url?q=https://vietnambiz.vn/xuat-khau-gao-st25-trongquy-i-2021-tang-375-lan-vuot-con-so-cua-ca-nam-202020210420195547707.htm\%23: :text\%3DGi\%25C3\%25A1\%2520g\%25E1\%25BA $\% 25 \mathrm{~A} 1 \mathrm{o} \% 2520 \mathrm{ST} 25 \% 2520 \mathrm{xu} \% 25 \mathrm{E} 1 \% 25 \mathrm{BA} \% 25 \mathrm{~A} 5 \mathrm{t} \% 2520 \mathrm{kh} \% 25 \mathrm{E} 1 \% 25 \mathrm{BA} \% 2$ $5 \mathrm{~A} 9 \mathrm{u} \% 252$.

[26] H. Hiệp, Xuất khẩu tăng hơn 800\%, gạo ST24 và ST25 hút hàng tại Mỹ và Trung Quốc, Vietnambiz. (2021). https://vietnambiz.vn/xuat-khau-tang-hon-800-gaost24-va-st25-hut-hang-tai-my-va-trung-quoc-20211102142744596.htm. 